\title{
Construção e validação de tecnologia educativa no formato de história em quadrinhos na área de imunizações: instrumento de autocuidado e de estímulo à vacinação infantil
}

\section{The construction and validation of educational technology in the format of comic books in the field of immunizations: an instrument for self-care and encouraging the vaccination of children}

(iD)

Claudio José dos Santos Júnior ${ }^{1}$

Silvio Nunes da Silva Júnior ${ }^{2}$

Paulo José Medeiros de Souza Costa'

\begin{abstract}
'Universidade Estadual de Ciências da Saúde de Alagoas (UNICSAL), Programa de Pós-Graduação em Ensino em Saúde e Tecnologia, Maceió, AL, Brasil. Autor correspondente: claudiojunioir@gmail.com

2Universidade do Estado da Bahia (UNEB), Programa de Pós-Graduação em Educação, Cultura, e Territórios Semiáridos, Juazeiro, BA, Brasil.
\end{abstract}

Resumo: Este trabalho consiste em um estudo metodológico que teve como objetivo construir e validar uma tecnologia educativa no formato de História em Quadrinhos $(\mathrm{HQ})$ na área de imunizações como estratégia de Educação e Comunicação em Saúde. O seu desenvolvimento envolveu duas fases: construção e validação. Na primeira fase foram cumpridas quatro subetapas: informativa, análise de similares, criativa, e arquitetura de informação. Na segunda, o material passou pela validação de conteúdo, realizada com sete juízes. A avaliação da $\mathrm{HQ}$ pelo comitê de especialistas evidenciou índice de validade global de conteúdo de 0,91, além de adequação metodológica e pedagógica do material e de contribuição cientifica e relevância de estrutura e de conteúdo. A construção da HQ figura, assim, como proposta de favorecer a vacinação e o saber do público infantojuvenil sobre aspectos relacionados à imunoprevenção e à Educação e Comunicação em Saúde no campo da vacinação infantil.

Palavras-chave: Vacinação; História em quadrinhos; Educação para a saúde; Tecnologia educacional.

Abstract: This is a methodological study that aimed to build and validate a type of educational technology in the format of a comic book area of immunizations as a strategy in Health Education and Communication. The development involved two phases: construction and validation. The first phase was completed following an informative substep, similarity analysis, a creative stage, and information architecture. In the second phase, the material went through content validation, performed with seven judges. The evaluation of the comics by the committee of experts showed a global content validity index of 0.91 , in addition to methodological and pedagogical adequacy of the material and scientific contribution and relevance of structure and content. The construction of the comics is, therefore, a proposal to promote vaccination and the knowledge that children and adolescents have about aspects related to immunoprevention, and Health Education and Communication in the field of childhood vaccination. technology.

Keywords: Vaccination; Comic books; Teaching materials; Health education; Educational 


\section{Introdução}

As vacinas são, reconhecidamente, medidas relevantes da medicina preventiva para proteger a população de doenças e infecções. Tais medidas têm contribuído para a diminuição das taxas de doenças comuns na infância e, em alguns casos, como no Brasil, até eliminaram patologias que geravam importantes impactos em termos de morbimortalidade, como é o caso da varíola e da poliomielite (HUSSAIN et al., 2018; NASSARALLA et al., 2019).

No entanto, nos últimos anos, tem havido um aumento nos movimentos intitulados antivacinação, que pautam suas ações nas crenças de que as vacinas causam mais danos do que benefícios à saúde das crianças que as recebem. Esses grupos contribuem para a demonização das vacinas e para a instalação de medo e de desconfiança na mente de pais e cuidadores, que acabam por se tornar hesitantes ao processo de vacinação (DUBÉ; VIVION; MACDONALD, 2015; SILVA; OLIVEIRA; GALATO, 2019).

A resistência à adesão das vacinas como estratégia de proteção individual e coletiva é relatada como responsável pela diminuição da cobertura vacinal de crianças e pela consequente reemergência de recentes surtos de patologias que se pensavam estarem 'eliminadas' (DRUZIAN et al., 2014; HUSSAIN et al., 2018; LEITE; BARRETO; SOUSA, 2015; ROCHA et al., 2015; ROMANO et al., 2014; SATO, 2018).

Esse cenário evidencia a necessidade da adoção de ações que tenham como finalidade alertar a população acerca da pertinência da vacinação como principal medida de controle das doenças imunopreveníveis e como única e mais efetiva estratégia capaz de evitar a reemergência de doenças anteriormente eliminadas (DOMINGUES et al., 2019; SILVA; OLIVEIRA; GALATO, 2019).

A Educação e Comunicação em Saúde visa, nesse contexto de educação em saúde vacinal, propiciar instrução e consequente cuidado emancipatório, capacitando o indivíduo para o autocuidado através da motivação, da interatividade, da significância do assunto, do dinamismo, do reforço na transmissão da informação e da educação continuada (GONÇALVES et al., 2008; MOURA et al., 2017). Compactua-se da ideia de que a educação deve contribuir para formar cidadãos e despertar responsabilidades, afirmação que se vincula à visão de que o papel da educação, em suas diversas dimensões, vai além da aquisição de conhecimentos e adentra no plano da transformação de ideologias, práticas e ações (DORNELAS; SOUSA; MENDONÇA, 2014).

Nessa linha de pensamento, o trabalho em tela pretende contribuir com uma atuação de saúde como recorte temático que dá contornos e especificidades à discussão educacional, afastando-se de uma visão generalista e instrumental do campo educativo, o que permite uma ampliação de olhares que abarca a relação entre educação, comunicação e saúde quando há a mobilização de saberes, anteriormente caracterizados como puramente científicos, para públicos diversos (MARTINS, 2019).

Em inter-relação com a saúde, compondo a área de Educação e Comunicação em Saúde, as tecnologias educativas podem estimular processos de construção de conhecimentos e, consequentemente, de modificação em realidades afetadas por diferentes discursos. Para a efetivação da articulação direta e necessária da educação com a comunicação no campo da saúde, especialmente para o público infantojuvenil, 
algumas áreas são também tomadas para auxiliar a disseminação desse debate, a exemplo da educação literária, quando o foco está no desenvolvimento de gêneros discursivos e/ou literários com destaque para temas socialmente relevantes.

Dessa maneira, o recurso à educação literária, quando envolve o cruzamento de modalidades de linguagem verbal, principalmente a escrita, e não-verbal, em especial a imagética, implica possibilidades de ampliar as alternativas de dinamização da pertinência da vacinação para a vida de modo bastante amplo. A literatura não é mais um jogo verbal que caracteriza a busca pelo conhecimento, mas um veículo de instrução sobre variados elementos sociais e culturais (ROCHA; LOPES, 2016). Dentro desse horizonte, a História em Quadrinhos (HQ) se apresenta como um gênero do discurso (BAKHTIN, 2016) capaz de contribuir com essa perspectiva, uma vez que sua estrutura, seus estilos e seus temas acabam se inter-relacionando e aproximando o tema da vacinação, que tem sua episteme no campo da Saúde, da leitura crítica do público infantojuvenil.

Para tal público, palavras, sentidos e recursos visuais precisam estar em sintonia para que os textos dispostos para crianças e jovens cumpram seus papeis, que são, antes de tudo, sociais. Trabalhos que agregam esses elementos são necessários, pois contribuem com reflexões já existentes sobre temas socialmente relevantes em materiais didáticos direcionados a diferentes públicos (SANTANA; SILVA JÚNIOR; FRANCELINO, 2020). Além disso, a elaboração de tecnologias educativas inserindo o tema da vacinação em HQs colabora para a superação de concepções de criança e de infância limitadas a abordagens ficcionais, o que tem sido comum na educação infantil, nível que representa a iniciação do aluno na escola (MARQUES; MARANDINO, 2019).

Este trabalho, ao propor a elaboração de uma tecnologia educativa para o público infantojuvenil, pressupõe que o empoderamento deste segmento constitui-se como um importante aliado para o autocuidado. Parte-se do princípio de que a criança precisa receber informações de saúde para construir certo grau de conhecimento sobre o processo saúde-doença e, assim, alcançar independência e autonomia necessárias para o autocuidado. Acredita-se, ademais, que a criança pode atuar como agente direto de sensibilização de seus cuidadores através da promoção e da multiplicação de cuidados em saúde (COSTA et al., 2018; GONÇALVES et al., 2008; MOURA et al., 2017).

Torna-se importante destacar que foi realizada revisão da literatura, por meio de consultas às principais bases de dados de produção de informação em saúde no âmbito nacional, e que não foram identificados trabalhos que mencionassem tecnologias educativas no formato impresso destinadas à Educação e Comunicação em Saúde do público infantojuvenil sobre o tema das imunizações.

Diante disso, no presente trabalho, foi realizada a construção e a validação de uma tecnologia educacional, no formato de História em Quadrinhos (HQ), na área de imunizações, com fim de suprir a lacuna mencionada.

\section{Procedimentos metodológicos}

Trata-se de estudo metodológico de desenvolvimento e validação de uma tecnologia educacional em forma de $\mathrm{HQ}$ acerca do tema imunizações. Em síntese, o estudo envolveu duas fases: (i) construção do material didático em saúde; e (ii) avaliação por comitê de experts. O estudo respeitou as diretrizes e normas regulamentadoras das pesquisas que envolvem seres humanos, respaldadas pela resolução n 510/16, de modo 
que, previamente ao início de suas etapas, foi submetido e aprovado pelo Comitê de Ética em Pesquisa da Universidade Estadual de Ciências da Saúde de Alagoas, através de CAAE n³ 30826320.5.0000.5011 e de Parecer Consubstanciado n 4.083.158.

A primeira fase refere-se ao desenvolvimento da tecnologia educacional. Nela, foram percorridos os procedimentos sugeridos por Motta (2012) e Lopes (2020), com adaptações. No total, quatro subetapas foram cumpridas: (a) etapa informativa; (b) análise de similares; (c) etapa criativa; e (d) arquitetura de informação. Tais estão esquematizadas na figura 1.

Figura 1 - Etapas do processo de desenvolvimento da tecnologia educacional em forma de história em quadrinhos

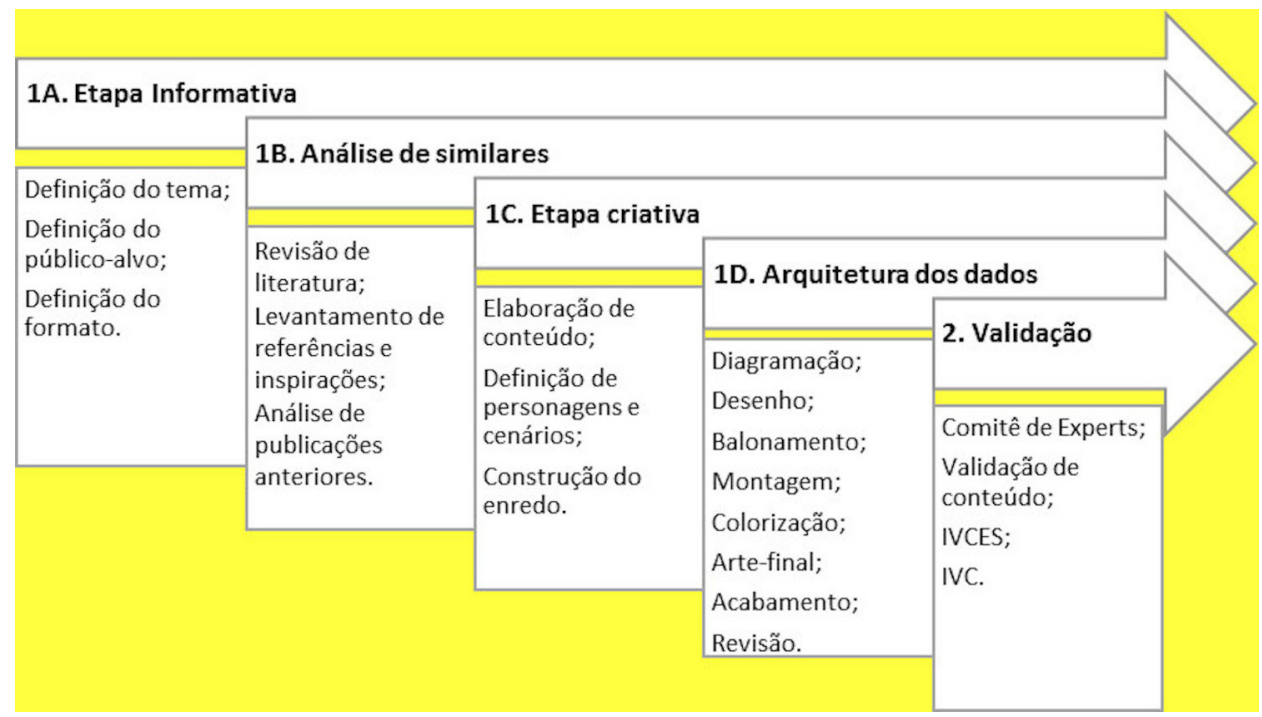

Fonte: adaptado de Motta (2012) e Lopes (2020).

Após a elaboração da tecnologia, realizou-se a validação da HQ através de consulta ao comitê de experts composto por sete juízes. Esse grupo de técnicos foi definido com base na literatura da área (LYNN, 1986) e contemplou quatro profissionais de saúde, sendo dois especialistas na área de saúde da criança e dois na área de saúde pública e/ou ensino na saúde; dois profissionais da área de educação e/ou pedagogia com expertise na produção e no uso de materiais didáticos para educação infantojuvenil; e um profissional da área de comunicação, com experiência em design de personagens, ilustrações e/ou design de livros, com atuação na produção de materiais para educação infantojuvenil.

Para a participação na pesquisa, os juízes foram selecionados por conveniência e deveriam contemplar os seguintes parâmetros: (i) qualificação mínima de pósgraduação stricto sensu; (ii) experiência de, no mínimo, cinco anos de atuação no seu segmento profissional e/ou área de atuação; (iii) experiência com produção e/ou uso de materiais didáticos para educação infantojuvenil e/ou Educação e Comunicação em Saúde; e (iv) disponibilidade para participação no estudo. Para os experts da área de saúde, foi definido, ademais, um quinto critério de inclusão: possuir experiência acadêmica, profissional e/ou de gestão na área de vacinas/imunizações.

A avaliação da tecnologia educacional pelos membros do comitê de experts foi realizada através de preenchimento do Instrumento de Validação de Conteúdo Educativo em Saúde (IVCES), um protocolo previamente validado para ser utilizado por pesquisadores e profissionais na construção de conteúdos educativos no campo da 
saúde (LEITE et al., 2018). Na análise do feedback do comitê de experts foi empregado o Índice de Validade de Conteúdo (IVC) para cada um dos itens do Instrumento. Adotouse IVC $\geq 0,78$ como concordância aceitável entre os juízes e IVC $<0,78$ como parâmetro indicativo da necessidade de revisão do item e/ou do aspecto analisado pelo comitê (ALEXANDRE; COLUCI, 2011).

Finalizada a etapa de validação do material, foi atribuída Licença Creative Commons BY-NC à tecnologia educacional, solicitado registro/depósito do recurso à Agência Brasileira do ISBN (International Standard Book Number) e realizada indexação no Repositório de Recursos Educacionais da Coordenação de Aperfeiçoamento de Pessoal de Nível (EduCapes). Procedeu-se, em seguida, com a distribuição da tecnologia educativa em sites, blogs e redes sociais e a divulgação em instituições de educação infantojuvenil da rede pública. A intenção dessa etapa foi disponibilizar o recurso não só para profissionais da área de saúde e membros da comunidade acadêmica, mas, também, para alcançar o público-fim do recurso educacional e a população em geral que possua interesse no tema.

\section{Resultados}

\section{Definição do conteúdo da tecnologia educacional}

Após definição do público, do tema e do formato da tecnologia educacional, partiu-se para fase de seleção do conteúdo e de análise de similares.

Para a escolha do conteúdo do material, reconhecendo a internet como importante meio de comunicação, realizou-se a análise do conteúdo virtual sobre o tema de interesse. A seleção resultou em dois portais como fonte de dados: o site Fake news sobre saúde, do Ministério da Saúde do Brasil (MS), e o Portal Família SBim, da Sociedade Brasileira de Imunizações (SBIm). O primeiro é um Canal Oficial do Governo Brasileiro para combater as fake news na área de saúde, cujas informações publicadas são apuradas pelo MS e são respondidas oficialmente se são verdadeiras ou falsas, sendo acompanhadas de fundamentação acadêmico-científica em linguagem de fácil acesso e leitura, e o segundo trata-se de uma enciclopédia virtual que disponibiliza, entre outros recursos, detalhes sobre as doenças imunopreveníveis e informações gerais sobre vacinas. Em ambos os casos, as informações fornecidas são fundamentadas em estudos desenvolvidos por técnicos de renomadas instituições na área de saúde. O Portal Família SBim é, ademais, o único no Brasil e em língua portuguesa acreditado pela Vaccine Safety Net (VSN), da Organização Mundial da Saúde (OMS), tendo sido reconhecido como único site em língua portuguesa apto a oferecer informações confiáveis sobre vacinação no Mundo.

Na seleção do conteúdo do material, buscou-se levantar, nas fontes de dados mencionadas, quais eram os principais mitos, tabus e inverdades que permeavam o tema das vacinas no território nacional. Realizou-se, ademais, consulta ao Estudo As fake news estão nos deixando doentes?, desenvolvido pela ONG Avaaz, em parceria com a SBIm, que apontou os principais conteúdos antivacinação, incorretos ou desinformativos, mais comuns nas redes sociais e nos aplicativos de mensagens (AVAAZ, 2019).

Essa etapa permitiu identificar as dúvidas e questionamentos mais frequentes por parte dos Brasileiros no âmbito do tema em estudo. Assim, identificou-se, 
consequentemente, as necessidades de informação sobre o tema vacinação. Foram onze os principais mitos, tabus e pontos que geram dúvidas em relação ao tema objeto da pesquisa: (i) vacinas causam mais doenças do que previnem; (ii) vacinas causam sempre efeitos colaterais graves; (iii) vacinas causam autismo; (iv) vacinas causam microcefalia; (v) quem não tem doença ou nunca adoeceu não precisa se vacinar; (vi) é perigoso tomar várias vacinas de uma vez; (vii) tomar apenas uma dose de uma vacina na vida é suficiente; (viii) não é preciso tomar mais vacina para doença erradicada no país; (ix) pessoas saudáveis e que se alimentam bem não precisam tomar vacinas; (x) grávidas não podem tomar vacinas; e (xi) quem perdeu alguma dose de vacina não pode mais se vacinar. Essas questões foram incorporadas ao roteiro da Tecnologia Educativa desenvolvida (figura 2) e abordadas ao longo da narrativa produzida.

Figura 2 - Capa da tecnologia educacional na modalidade História em Quadrinhos sobre o tema imunizações

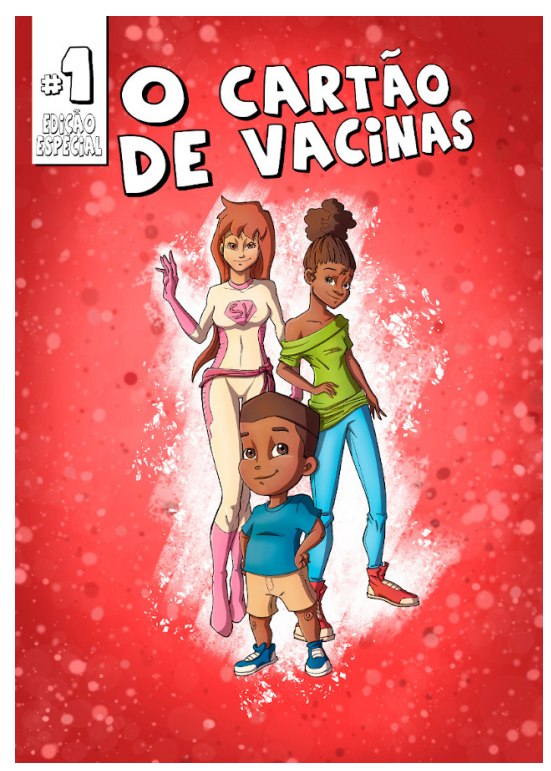

Fonte: elaborado pelos autores.

$\mathrm{Na}$ análise de referências anteriores e inspirações estéticas, foram selecionadas duas propostas de materiais já produzidos no Brasil que dialogavam com os objetivos do Estudo e com o formato escolhido para elaboração da Tecnologia Educacional: a Revista Sesinho e Sua Turma, elaborada pelo SESI e pela Federação das Indústrias, e a Revista Turma da Mônica, de autoria do cartunista Maurício de Souza, reconhecido como o maior nome no ramo dos quadrinhos no território nacional. Dessas obras foram retiradas inspirações artísticas para a composição do binômio texto-imagem e estratégias para tornar atraente a leitura da HQ produzida, aproximando-a do públicoalvo pretendido.

\section{Estruturação da tecnologia educacional}

A Tecnologia Educacional foi intitulada O cartão de vacinas, em referência à sua cena inicial, momento em que a personagem principal, Carlinhos, de quatro anos, tenta esconder sua caderneta de vacinação de sua mãe para não tomar a dose de reforço da vacinal oral da poliomielite (VOP). A partir desse ponto, desenvolve-se o enredo da narrativa e Carlinhos passa a questionar sua irmã mais velha, a personagem Manu, sobre um conjunto de pontos envolvendo as vacinas, sua relevância e utilidade. 
$\mathrm{Na}$ abordagem da HQ O cartão de vacinas, priorizou-se frases curtas, com palavras que fazem parte do cotidiano dos leitores da faixa etária infantojuvenil, além da voz ativa. No enredo, evitou-se o uso de jargões e termos técnicos, priorizando, assim, ações positivas, informando ao leitor do material o que é verdade e o que é 'mito' acerca do tema das imunizações. Todas as falas das personagens do HQ são voltadas, igualmente, para valorização das vacinas como ferramentas vitais para a promoção da saúde pública.

As ilustrações na HQ foram utilizadas para representar o conteúdo escrito, atribuindo significado as falas das personagens e com fins de facilitar o aprendizado do tema proposto, tendo sido inseridas, ao longo de toda história, personagens representando germes causadores de doenças - e que são prevenidos pelas vacinas -, além de outras personagens, como o conhecido Zé Gotinha, mascote nacional das campanhas de vacinação do MS. Foi criada, ademais, a personagem Super Mulher Vacina, a heroína das vacinas, e responsável pela imunização de todas as crianças do mundo e pela proteção do Planeta contra as doenças imunopreveníveis (figura $\mathbf{3}$ ).

Figura 3 - Trechos da tecnologia educacional na modalidade História em Quadrinhos sobre o tema Imunizações
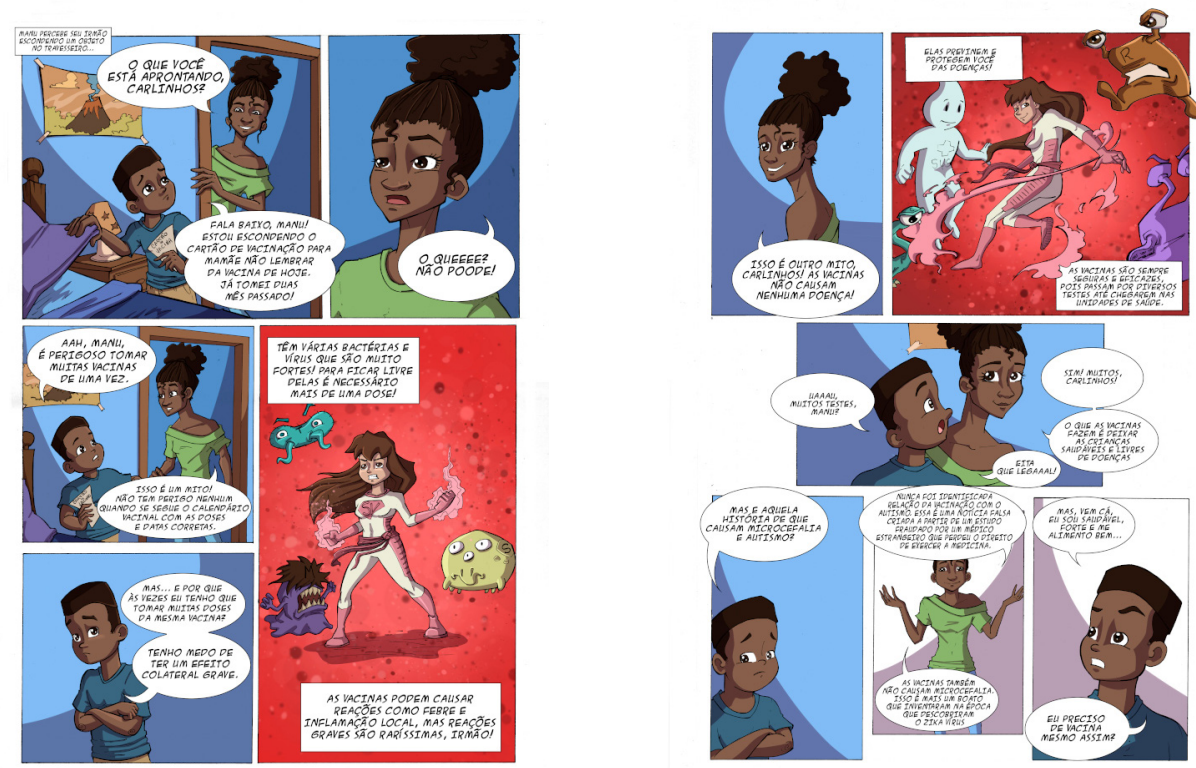

Personagens presentes na narrativa: germes causadores de doenças, Super Mulher Vacina e Zé Gotinha.

Fonte: elaborado pelos autores.

Na confecção das figuras foram empregados desenhos de linhas simples, criados inicialmente de forma manual e posteriormente no software Photoshop, mesmo programa que foi utilizado para editoração e colorização do material - etapa em que se optou por cores vivas, nos tons vermelho, azul e verde.

\section{Validação de conteúdo pelo comitê de experts}

Finalizada a confecção, a HQ foi avaliada pelo comitê de especialistas. No total, participaram da avaliação sete profissionais. A qualificação dos profissionais que atuaram no processo de validação de conteúdo em termos de profissão, área e subárea 
de atuação, tempo de desempenho das atividades profissionais na área e titulação, estão dispostas no quadro 1.

Quadro 1 - Caracterização dos participantes da etapa comitê de experts da História em Quadrinhos $O$ cartão de vacinas

\begin{tabular}{|l|l|l|c|c|l|}
\hline \multirow{2}{*}{ Juiz(a) } & \multicolumn{3}{|c|}{ Formação } & \multicolumn{3}{c|}{ Atuação Profissional } \\
\cline { 2 - 6 } & \multicolumn{1}{|c|}{ Profissão } & Formação & Tempo & \multicolumn{1}{c|}{ Área } & \multicolumn{1}{c|}{ Subáreas } \\
\hline 01 & Enfermagem & Doutorado & 17 & Saúde & Saúde Pública \\
\hline 02 & Enfermagem & Mestrado & 12 & Saúde & Pediatria \\
\hline 03 & Medicina & Mestrado & 21 & Saúde & Pediatria \\
\hline 04 & Medicina & Doutorado & 40 & Saúde & Ensino na Saúde \\
\hline 05 & Desenho Industrial & Mestrado & 15 & Design & Design de Produto \\
\hline 06 & Pedagogia & Doutorado & 20 & Educação & Educação infantojuvenil \\
\hline 07 & Pedagogia/Licenciatura & Mestrado & 23 & Educação & Educação infantojuvenil \\
\hline
\end{tabular}

Fonte: elaborado pelos autores.

$\mathrm{Na}$ avaliação, os experts realizaram enquadramento do recurso em dezoito parâmetros do IVCES. Nos itens sugestões, comentários e pontos fortes e fracos foram recomendadas, no geral, adequações na linguagem do material, com ênfase para substituição de vocábulos. Termos como 'evento adverso' e equivalentes foram substituídos por 'efeito colateral' ou 'reações', os quais, apesar de não se tratarem de termos empregados costumeiramente na área, são amplamente conhecidos na linguagem popular, por serem relacionados aos eventos indesejados causados por um medicamento ou vacina. Expressões como 'calendário vacinal', 'imunização' e nomes de patologias que comumente são vinculadas às notícias falsas (exemplo 'microcefalia' e 'autismo'), apesar de não fazerem parte do vocabulário usual do público infantojuvenil, foram mantidos pelo caráter informativo e, ao mesmo tempo, educativo do material produzido, o qual, para além de esclarecer dúvidas sobre o tema abordado, visa estimular o aprendizado e despertar o interesse pelo tema e a curiosidade por parte dos leitores. Igualmente, houve a sugestão de substituição da expressão 'fake news', tendo sido esta substituída pelo termo 'mito' - expressão utilizada pelo Ministério da Saúde e pela SBim para rotular informações falsas sobre as vacinas.

Outros ajustes na arquitetura do material foram recomendados pela equipe de especialistas, tendo sido incorporados ao material, com a finalidade de promover melhor harmonização entre texto-imagem-sentido da HQ e de gerar identificação do leitor com o material produzido. A descrição dessas alterações está sumarizada no quadro 2. 
Quadro 2 - Alterações realizadas na História em Quadrinhos O cartão de vacinas sugeridas pelo Comitê de Experts

\begin{tabular}{|l|l|}
\hline \multicolumn{1}{|c|}{ Aspecto } & \multicolumn{1}{c|}{ Descrição da alteração promovida } \\
\hline Estrutura & $\begin{array}{l}\text { Foram aumentados os espaços deixados entre um quadrinho e outro, conferindo uma ideia de transição ao roteiro } \\
\text { e de 'unidade de atenção' aos diferentes momentos da HQ. Essa alteração, igualmente, visou fomentar o design } \\
\text { das páginas do HQ e a lógica de leitura do material: da esquerda para a direita e de cima para baixo, além de } \\
\text { reforçar o caráter sequencial da história. }\end{array}$ \\
\hline Balonização & $\begin{array}{l}\text { Realizou-se a padronização do formato dos balões com fins de melhor definir os diálogos entre as personagens } \\
\text { da HQ e suas ideias. }\end{array}$ \\
\hline Traço e cor & $\begin{array}{l}\text { Nos traços, o emprego inicial da técnica de hachuras e das linhas de sombreamento em certos momentos da } \\
\text { narrativa, além dos tons monocromáticos, foi substituído por texturas densas e coloridas, em sua maioria nos } \\
\text { tons vermelho, azul e verde, com fins de aproximar o material produzido aos cartoons e gibis, categorias de HQ } \\
\text { direcionadas para o público infantojuvenil. }\end{array}$ \\
\hline Personagens & $\begin{array}{l}\text { Os germes causadores de doenças tiveram seu tamanho e forma adaptados. O traço dos desenhos dessas personagens } \\
\text { foi caracterizado pelo exagero dos olhos, nariz e boca com objetivo de atribuir-lhes marcante e intuitivo estilo } \\
\text { narrativo, além de expressividade e caracterização visual desses seres, muitas vezes abstratos, pelo seu caráter } \\
\text { microscópico e invisível a olho nu. Essa modificação está alinhada a função social da HQ e se traduz pelo 'código' } \\
\text { de que esses são seres do mal, que causam doenças e são prejudiciais à saúde. Visa-se reforçar a mensagem de } \\
\text { que tais microrganismos precisam ser prevenidos, neste caso pelas imunizações, entendidas ao longo do roteiro } \\
\text { como ferramenta para a promoção da saúde e do bem estar. }\end{array}$ \\
\hline
\end{tabular}

Fonte: elaborado pelos autores.

O recurso obteve IVC total de 0,91, IVC 0,90 na dimensão objetivos, IVC 0,95 na dimensão estrutura e IVC 0,91 na dimensão relevância, sendo classificado com status final de 'validado'. O IVC geral, por item e por dimensão, segundo parâmetros de validação de conteúdo do IVCES, está apresentado no quadro 3.

Quadro 3 - Validação da História em Quadrinhos O cartão de vacinas pelo comitê de experts segundo parâmetros de validação de conteúdo

\begin{tabular}{|l|l|}
\hline \multicolumn{1}{|c|}{ Item / Dimensão } & IVC \\
\hline Objetivos do Recurso & $\mathbf{0 , 9 1}$ \\
\hline 1. Contempla tema proposto & 1,00 \\
\hline 2. Adequado ao processo de ensino-aprendizagem & 0,86 \\
\hline 3. Esclarece dúvidas sobre o tema abordado & 1,00 \\
\hline 4. Proporciona reflexão sobre o tema & 0,86 \\
\hline 5. Incentiva mudança de comportamento & 0,86 \\
\hline Estrutura/Apresentação do Recurso & $\mathbf{0 , 9 0}$ \\
\hline 6. Linguagem adequada ao público-alvo & 0,86 \\
\hline 7. Linguagem apropriada ao material educativo & 0,86 \\
\hline 8. Linguagem interativa, permitindo envolvimento ativo no processo educativo & 0,86 \\
\hline 9. Informações corretas & 1,00 \\
\hline 10. Informações objetivas & 1,00 \\
\hline 11. Informações esclarecedoras & 0,86 \\
\hline 12. Informações necessárias & 1,00 \\
\hline 13. Sequência lógica das ideias & 0,86 \\
\hline 14. Tema atual & 0,86 \\
\hline 15. Tamanho do texto adequado & 0,86 \\
\hline Relevância do Recurso & $\mathbf{0 , 9 5}$ \\
\hline 16. Estimula o aprendizado & 0,86 \\
\hline 17. Contribui para o conhecimento na área & 1,00 \\
\hline 18. Desperta interesse pelo tema & 1,00 \\
\hline IVC Total & $\mathbf{0 , 9 1}$ \\
\hline
\end{tabular}

Fonte: elaborado pelos autores. 


\section{Distribuição da tecnologia educativa}

A Tecnologia Educativa validada pelo comitê de especialistas se encontra disponível, de forma gratuita e on-line, para leitura, download e compartilhamento, no Repositório de Recursos Educacionais da Coordenação de Aperfeiçoamento de Pessoal de Nível Superior (SANTOS JÚNIOR; COSTA, 2021) e no site do Mestrado Profissional em Ensino na Saúde e Tecnologia da Universidade Estadual de Ciências da Saúde de Alagoas, para ser consultada por pais, professores, crianças, e pelo público em geral.

$\mathrm{Na}$ perspectiva da construção do conhecimento e com a finalidade de proporcionar uma leitura ativa e dinâmica, foi desenvolvida, ademais, uma segunda versão do material $O$ cartão de vacinas - para colorir, que dispõe de atividades de pintura para serem realizadas pelos leitores do material primário. Essa segunda versão surge como mecanismo de potencializar o lúdico e a interação do leitor com o conteúdo, personagens e mensagens trazidas na HQ. A finalidade é a de que as crianças, que tenham ou não desenvolvido a habilidade da leitura, e o público em geral possam interagir com o material e, assim, se identificarem com a narrativa apresentada, potencializando o papel do recurso e, consequentemente, sua mensagem principal: a valorização das vacinas como estratégia de saúde e de proteção individual e coletiva.

\section{Discussão}

Diante da necessidade de constante renovação nos modelos de educação, observa-se uma tendência no desenvolvimento e aplicação de novas estratégias no campo da Educação e Comunicação em Saúde. Este trabalho se insere nessa vertente e buscou o desenvolvimento e a validação de uma tecnologia educativa no formato de HQ para ser utilizada como recurso-meio de estímulo à vacinação infantil e de promoção da saúde.

As HQs, segundo Prado, Sousa Junior e Pires (2017), possuem uma linguagem própria e acessível ao público infantojuvenil, além de contribuírem para o desenvolvimento da relação entre leitor e texto e de incentivarem uma melhor compreensão de temas das mais variadas áreas do conhecimento humano. Para os autores, ao adaptar a estrutura desses recursos e incluir a leitura de HQs no contexto da área de saúde, especialmente na Educação e Comunicação em Saúde voltada para o público infantojuvenil, o educador em saúde, ou ainda o profissional da área de ensino, pode tornar suas práticas mais interessantes, além de contribuir positivamente para a apreensão de conceitos e para a adoção de mudanças de hábitos. Em concordância, Andraus (2010) destaca que as HQs constituem-se enquanto ferramentas de comunicação versáteis e eficazes, pois estimulam a atividade de ambos os hemisférios do encéfalo humano através de imagens e de texto. O autor endossa a efetividade desses recursos ressaltando os múltiplos elementos representativos e a riqueza verbal e não verbal dos quadrinhos em vista de transmitir um conteúdo-alvo. Para ele, além de explicar e instruir sobre cuidados em saúde, as HQs atuam no próprio processo de promoção de saúde, pois, ao ler, o usuário do material aprende cuidados que o ajudarão a ter hábitos mais saudáveis, preservando sua saúde.

A relação entre o verbal e o não-verbal, principalmente no que se refere à articulação texto-imagem, traz subsídios relevantes para o processo de aprendizagem. Dentre eles, a leitura crítica possibilita o acesso a informações relativas aos benefícios 
da vacinação para a saúde de toda a sociedade. Além disso, a presença de temas socialmente relevantes nas HQs pode levar os docentes a identificarem o seu potencial uso em situações de ensino que gerem maior reflexão sobre as questões de saúde que impactam (in)diretamente na qualidade de vida da coletividade. Cabe ressaltar, ainda, que as imagens têm uma grande significação por retratarem reações, diálogos e ações que não são distantes das realidades das crianças, facilitando os processos de compreensão. Essas retratações contribuem, além disso, para a curiosidade e o envolvimento dos indivíduos na realização de leituras críticas e efetivas das HQs, o que reitera o compromisso social da educação literária (ROCHA; LOPES, 2016).

No caso concreto, buscou-se, por meio da tecnologia O cartão de vacinas, estimular o reconhecimento de crianças de que as imunizações são ferramentas vitais para a promoção da saúde e do bem estar individual e coletivo, esclarecendo inverdades acerca do tema e estimulando o raciocínio crítico acerca de fake news não raramente divulgadas sobre as vacinas infantis. Essa ação fundamenta-se nas ideias de Silva et al. (2018), que propõem a formação de 'multiplicadores', na perspectiva das competências da promoção da saúde, estando, também, em contraste às práticas de cuidados infantis embasadas por concepções higienistas (AMORIM et al., 2019; MARTINS, 2019). Está, igualmente, em concordância com a prática educativa sugerida por Paulo Freire, que pressupõe a chamada pedagogia da autonomia, em que as atividades de ensino e, por consequência, de Educação e Comunicação em Saúde, devem ser focadas em práticas estimuladoras de decisão e de comprometimento social (OLIVEIRA; COTA, 2018) - no caso concreto, no reconhecimento da importância e na procura de uma condição saudável através do reconhecimento de que as vacinas são eficientes medidas de garantia da saúde coletiva e individual.

A possibilidade da utilização das HQs no campo da Educação e Comunicação em Saúde, como no presente trabalho, foi identificada através da revisão da literatura especializada, em um estudo no Brasil datado de 1983. Nesse trabalho, crianças de 10 anos de idade, residentes em Londrina, PR, receberam um material instrucional na área de odontologia sob a forma de HQ. Buscava-se investigar se a HQ elaborada exercia algum fator de influência na modificação dos comportamentos dos participantes em relação à higiene oral. Para tanto, empregou-se a avaliação do índice de placa bacteriana e de entrevistas clínicas com as crianças participantes. Os resultados da pesquisa mostraram que houve modificação nos hábitos de higiene oral, com diminuição do índice de placa bacteriana no grupo de crianças que leram a $\mathrm{HQ}$ (CARVALHO, 1983a, 1983b). Em outros estudos, também ficou assentada a eficácia da HQ em informar crianças de 6 a 10 anos sobre distúrbios do sono, em informar crianças com aproveitamento escolar normal e com déficit de aprendizagem sobre questões relativas à higiene do sono e no conhecimento de escolares sobre aleitamento materno (CAMARGO, 2012, 2015; LEÃO et al., 2018). Outros trabalhos mais recentes também propõem utilizar essa estratégia para comunicar temas da área de saúde de interesse social e/ou que apresentam difícil abordagem e/ou importante grau de abstração (CORRÊA et al., 2016; CRUZ et al., 2019; SEZEFREDO et al., 2016).

Assim, propõe-se a utilização de $O$ cartão de vacinas para 'incitar', desde logo, debates sobre a importância das imunizações, atuando de encontro aos movimentos que contribuem para demonização das vacinas e para a instalação de medo e de desconfiança nessas que são um dos maiores avanços que se tem conhecimento 
desde o surgimento do homem no planeta. Objetiva-se, com o uso da $\mathrm{HQ}$, formar multiplicadores em saúde, em especial na área de vacinas, como estratégia de enfretamento dos mitos e tabus que cercam o tema. Na educação infantojuvenil, o recurso desenvolvido poderá ser empregado em escolas, creches, unidades de saúde e em ações intersetoriais desenvolvidas por serviços da rede socioassistencial para abordagem dos cuidados com a saúde, estimulando um desenvolvimento integral e saudável desde cedo, além de um saber crítico. Essas ações poderão ser planejadas e desenvolvidas por professores e pela equipe pedagógica em conjunto com serviços da rede local de saúde, a exemplo daqueles que integram a Atenção Primária.

A avaliação dos especialistas evidenciou que a tecnologia educativa se constituiu em um material pertinente e válido em relação ao seu conteúdo com IVC global de 0,91 . Na avaliação do comitê, a HQ O cartão de vacinas: (i) contempla o tema proposto; (ii) é adequada ao processo de ensino-aprendizagem; (iii) esclarece dúvidas sobre o conteúdo de interesse e proporciona reflexões acerca do mesmo; e (iv) incentiva mudança de comportamento. A tecnologia educativa é adequada ao público-alvo e ao formato do recurso, é interativa e traz informações corretas, necessárias, objetivas e esclarecedoras e, além disso, apresenta lógica de construção, tamanho adequado, tema contemporâneo e estimula o interesse pelo assunto.

Por fim, faz-se importante destacar que a ação final esperada com a HQ desenvolvida é que o público possa agir positivamente no processo de adesão às vacinas, ampliando a cobertura vacinal, contribuindo para melhoria do conhecimento da sociedade no tema e para adoção de práticas de autocuidado e de imunoprevenção à saúde. O estudo está em consonância com as recomendações da Organização das Nações Unidas para a Educação, a Ciência e a Cultura que apontam a promoção da saúde na educação infantojuvenil como caminho para o desenvolvimento das nações e como meio de incluir a criança e seus pais na criação de ambientes que estimulem o desenvolvimento global, que favoreçam a adoção de estilos de vida saudáveis e de condutas de promoção do bem-estar e da proteção da vida (UNESCO, 2002).

\section{Limitações}

Este estudo possui limitações. Primeiro, ressalta-se que o objetivo primário foi de construir e validar um material educativo, não tendo sido contemplada a etapa de avaliação do recurso pela comunidade-alvo. Essa etapa, chamada de validação de face, não fez parte do delineamento proposto na pesquisa. Em segundo lugar, a despeito da validade de conteúdo ser um parâmetro fundamental no processo de desenvolvimento e validação de conteúdos educativos e de objetos de aprendizagem, esta apresenta limitações por ser um processo subjetivo e por ser avaliador dependente.

A despeito dessas considerações, adotamos uma metodologia estruturada tanto para o desenvolvimento do recurso quanto para a sua validação. Foi empregado um conjunto de indicadores referentes ao conteúdo, à linguagem e às potencialidades pedagógicas, que foram avaliados por especialistas através de um instrumento validado e referenciado pela literatura da área como adequado para avaliação de conteúdo educativo em saúde - o IVCES -, o que, em última análise, colabora com as evidências de validade de conteúdo apresentadas, tornando-as mais robustas. 


\section{Contribuições}

A construção da HQ O cartão de vacinas apresenta-se como proposta de favorecer a vacinação e o saber do público infantojuvenil, dos seus familiares e da comunidade escolar sobre aspectos relacionados à imunoprevenção e à Educação e Comunicação em Saúde no campo das imunizações. Novos estudos poderão ser realizados a fim de verificar a eficácia da tecnologia educacional como promotora do conhecimento na área de Educação e Comunicação em Saúde sobre o tema das vacinas, adesão à vacinação e estímulo ao autocuidado de crianças, além de mudança de comportamento de pais hesitantes às vacinas pós-contato com o material confeccionado. Pode-se, ainda, investigar se a $\mathrm{HQ}$ elaborada exerce algum fator de influência na modificação dos comportamentos/conhecimentos dos usuários do recurso e/ou de seus familiares em relação à vacinação infantil.

\section{Considerações finais}

A HQ O cartão de vacinas foi validada por meio de escala de validação de conteúdo educativo em saúde, alcançando índice de validade global de conteúdo de $91 \%$ (IVC=0,91) e evidências de adequação metodológica e pedagógica, além de contribuição científica e de relevância de estrutura e conteúdo.

Esse tipo de tecnologia pode funcionar como suporte às crianças e famílias para que superem dúvidas, distorções e fake news na área de saúde e, no caso concreto deste trabalho, no campo das imunizações, o qual tem sido tão afetado pelo fenômeno das notícias falsas.

\section{Agradecimentos}

Os autores agradecem especialmente aos juízes que atuaram no comitê de especialistas e à Pró-Reitoria de Pesquisa e Pós-Graduação da Universidade Estadual de Ciências da Saúde de Alagoas, pelo apoio dado ao desenvolvimento deste estudo.

\section{Referências}

ALEXANDRE, N. M. C.; COLUCI, M. Z. O. Validade de conteúdo nos processos de construção e adaptação de instrumentos de medidas. Ciência e Saúde Coletiva, Rio de Janeiro, v. 16, n. 7, p. 3061-3068, 2011. DOI: https://doi.org/fpc6r9.

AMORIM, D. S.; SANTOS, R. F.; WARDENSKI, R. F.; SILVA, L. M.; MARCÍLIO, R. O. D.; GIANNELLA, T. R. Discutindo saúde na escola a partir das concepções dos alunos: novas abordagens para ampliar concepções prévias. In: ENCONTRO NACIONAL DE PESQUISA EM EDUCAÇÃO EM CIÊNCIAS, 12., 2019, Natal. Anais [...]. Rio de Janeiro: Abrapec, 2019. p. 1-7. Disponível em: https://cutt. ly/4Qn6iiu. Acesso em: 5 ago. 2021.

ANDRAUS, G. Atualizando a educação: as histórias em quadrinhos e a importância das imagens para um equilíbrio sistêmico dos hemisférios direito e esquerdo do cérebro. Educação \& Linguagem, São Paulo, v. 13, n. 22, p. 169-191, 2010. DOI: https://doi.org/gnpx.

AVAAZ. As fake news estão nos deixando doentes?: como a desinformação antivacinas pode estar reduzindo as taxas de cobertura vacinal no Brasil. [São Paulo]: AVAAZ: SBim, 2019. Disponível em: https://cutt.ly/XmJX9bH. Acesso em: 15 jul. 2021.

BAKHTIN, M. Os gêneros do discurso. São Paulo: Editora 34, 2016. 
CAMARGO, E. P. História em quadrinhos para educação em saúde: um olhar sobre o leitor com déficit de aprendizagem. Anais Eletrônicos das Jornadas Internacionais de Histórias em Quadrinhos, São Paulo, v. 3, p. 1-10, 2015. Disponível em: https://cutt.ly/hmJ1dO1. Acesso em: 15 jul. 2021.

CAMARGO, E. P. Histórias em quadrinhos para educação em saúde: desenvolvimento e avaliação aplicados aos distúrbios do sono. 2012. 226 f. Tese (Doutorado em Ciências) - Universidade Federal de São Paulo, São Paulo, 2012. Disponível em: http://repositorio.unifesp.br/ handle/11600/22202. Acesso em: 15 jul. 2021.

CARVALHO, H. J. Modificação no habito de higiene bucal, motivada pela leitura de história era quadrinhos: parte I. Odontologia Moderna, Brasil, v. 10, n. 4, p. 25-37, 1983 a.

CARVALHO, H. J. Modificação no habito de higiene bucal, motivada pela leitura de história em quadrinhos: parte II. Odontologia Moderna, Brasil, v. 10, n. 5, p. 29-41, 1983b.

CORRÊA, A. D.; RÔÇAS, G.; LOPES, R. M.; ALVES, L. A. A utilização de uma história em quadrinhos como estratégia de ensino sobre o uso racional de medicamentos. Alexandria, Florianópolis, v. 9, n. 1, p. 83, 2016. DOI: https://doi.org/gnpz.

COSTA, C. I. A.; PACHECO, S. T. A.; SOEIRO, G.; ADAME, D. G.; PERES, P. L.P.; ARAÚJO, B. B. M. Construção e validação de materiais educativos para criança com doença crónica: uma revisão integrativa. Revista Enfermagem UERJ, Rio de Janeiro, v. 26, p. 1-7, 2018. Disponível em: https:// cutt.ly/amJLqY1. Acesso em: 15 jul. 2021.

CRUZ, G. C. V.; VASCONCELOS, M. G. F.; MANIVA, S. J. C. F.; CARVALHO, R. E. F. L. Construction and validation of an educational technology on human papillomavirus vaccine for adolescents. Escola Anna Nery, Rio de Janeiro, v. 23, n. 3, P. 1-7, 2019. DOI: https://doi.org/gnp2.

DOMINGUES, C. M. A. S.; FANTINATO, F. F. S. T.; DUARTE, E.; GARCIA, L. P. Vacina Brasil e estratégias de formação e desenvolvimento em imunizações. Epidemiologia e Serviços de Saúde, Brasília, v. 28, n. 2, e20190223, p. 1-4, 2019. DOI: https://doi.org/gnp3.

DORNELAS, R.; SOUSA, M. F.; MENDONÇA, A. V. M. Informação, educação e comunicação em saúde: análise das concepções dos coordenadores das campanhas de voz no Distrito Federal. Revista CEFAC, São Paulo, v. 16, n. 1, 274-282, 2014. DOI: https://doi.org/gqrb.

DRUZIAN, A. F. et al. Pertussis in the central-west region of Brazil: one decade study. Brazilian Journal of Infectious Diseases, Salvador, v. 18, n. 2, p. 177-180, 2014. DOI: https://doi.org/f2n5jb.

DUBÉ, E.; VIVION, M.; MACDONALD, N. E. Vaccine hesitancy, vaccine refusal and the anti-vaccine movement: influence, impact and implications. Expert Review of Vaccines, London, v. 14, n. 1, p. 99-117, 2015. DOI: https://doi.org/10.1586/14760584.2015.964212.

GONÇALVES, F. D.; CATRID, A. M. F.; VIEIRA, N. F. C.; VIEIRA, L. J. E. S. A promoção da saúde na educação infantil. Interface: comunicação, saúde, educação, Botucatu, v. 12, n. 24, p. 181-192, 2008. DOI: https://doi.org/bt47t2.

HUSSAIN, A.; ALI, S.; AHMED, M.; HUSSAIN, S. The anti-vaccination movement: a regression in modern medicine. Cureus, Bethesda, v. 10, n. 7, 2018. DOI: https://doi.org/10.7759/cureus.2919.

LEÃO, M. K. S.; FRANCO, M. S.; SOUSA, G. B.; NOBRE, R. S.; VALE, H. S.; LIMA, L. H. O. Efeitos de intervenção educativa no conhecimento de escolares sobre aleitamento materno. Saúde Coletiva, Santana do Parnaíba, v. 10, n. 57, p. 3705-3716, 2018. DOI: https://doi.org/gnp4.

LEITE, R. D.; BARRETO, J. L. T. M. S.; SOUSA, A. Q. Measles reemergence in Ceará, Northeast Brazil, 15 years after elimination. Emerging Infectious Diseases, Washington, v. 21, n. 9, p. 1681-1683, 2015. DOI: https://doi.org/10.3201/eid2109.150391.

LEITE, S. S.; ÁFIO, A. C. E.; CARVALHO, L. V.; SILVA, J. M.; ALMEIDA, P. C.; PAGLIUCA, L. M. F. Construction and validation of an educational content validation instrument in health. Revista Brasileira de Enfermagem, Brasília, v. 71, sup. 4, p. 1635-1641, 2018. DOI: https://doi. org/10.1590/0034-7167-2017-0648. 
LOPES, L. Como são feitas as histórias em quadrinhos? Galileu, Rio de Janeiro, 3 fev. 2020. Disponível em: https://cutt.ly/QmJ0ikk. Acesso em: 3 nov. 2020.

LYNN, M. R. Determination and quantification of content validity. Nursing Research, New York, v. 35, n. 6, p. 382-386, 1986.

MARQUES, A. C. T. L.; MARANDINO, M. Alfabetização científica, criança e espaços de educação não formal: diálogos possíveis. Educação e Pesquisa, São Paulo, v.44, n. 21, p. 1-19, 2018. DOl: https://doi.org/gnp5.

MARTINS, I. Educação em ciências e educação em saúde: breves apontamentos sobre histórias, práticas e possibilidades de articulação. Ciência \& Educação, Bauru, v. 25, n. 2, p. 269-275, 2019. DOI: https://doi.org/gnp6.

MOTTA, R. L. Metodologia de design aplicada à concepção de histórias em quadrinhos digitais. 2012. 159 f. Dissertação (Mestrado em Design) - Universidade Federal de Pernambuco, Recife, 2012.

MOURA, D. J. M.; MOURA, N. S.; MENEZES, L.C.G.; BARROS, A. A.; GUEDES, M. V. C. Development of a booklet on insulin therapy for children with diabetes mellitus type 1. Revista Brasileira de Enfermagem, Brasília, v. 70, n. 1, p. 7-14, 2017. Disponível em: https://cutt.ly/oQHwleQ. Acesso em: 13 ago. 2021.

NASSARALLA, A. P. A.; DOUMIT, A. M.; MELO, C. F.; LEÓN, L. C.; VIDAL, R. A. R.; MOURA, L. R. Dimensões e consequências do movimento antivacina na realidade brasileira. Revista Educação em Saúde, Anápolis, v. 7, n. 1, p. 120-125, 2019. Disponível em: https://cutt.ly/gmJz0zv. Acesso em: 15 jul. 2021.

OLIVEIRA, M. F.; COTA, L. G. S. A pedagogia freiriana nas práticas de educação em saúde. Diversitates, Niterói, v. 10, n. 1, p. 46-58, 2018. Disponível em: https://cutt.ly/ZmJ0FAt. Acesso em: 15 jul. 2021.

PRADO, C. C.; SOUSA JUNIOR, C. E.; PIRES, M. L. Histórias em quadrinhos: uma ferramenta para a educação e promoção da saúde. RECIIS: revista eletrônica de comunicação, informação e inovação em saúde, Rio de Janeiro, v. 11, n. 2, 2017. DOI: https://doi.org/gnqc.

ROCHA, H. A. L. et al. Factors associated with non-vaccination against measles in northeastern Brazil: clues about causes of the 2015 outbreak. Vaccine, Dordrecht, v. 33, n. 38, p. 4969-4974, 2015. DOI: https://doi.org/10.1016/j.vaccine.2015.07.027.

ROCHA, P. A.; LOPES, R. V. N. Literatura infanto-juvenil: história e relações com a pedagogia. Revista Querubim, Niterói, n. 12, n. esp., p. 1-6, 2016. Disponível em: https://cutt.ly/3mJ2rQh. Acesso em: 15 jul. 2021.

ROMANO, A. P. M. et al. Yellow fever outbreaks in unvaccinated populations, Brazil, 20082009. PLoS Neglected Tropical Diseases, San Francisco, v. 8, n. 3, e2740, 2014. DOI: https://doi. org/10.1371/journal.pntd.0002740.

SANTANA, W. K. F.; SILVA JÚNIOR, S. N.; FRANCELINO, P. F. Perspectiva dialógica no livro didático de língua portuguesa: um estudo discursivo. Prolíngua, João Pessoa, v. 15, n. 1, p. 119-133, 2020. DOI: https://doi.org/gnp8.

SANTOS JÚNIOR, C. J.; COSTA, P. J. M. S. História em quadrinhos: "o cartão de vacinas". Maceió: UNCISAL, 2021. Livro digital. Disponível em: https://educapes.capes.gov.br/handle/ capes/585675. Acesso em: 15 jul. 2021.

SATO, A. P. S. What is the importance of vaccine hesitancy in the drop of vaccination coverage in Brazil? Revista de Saúde Pública, São Paulo, v. 52, 2018. DOI: https://doi.org/ghqkbt.

SEZEFredo, T. S.; MURATA, F. H. A.; PERESI, J. T. M.; PASCHOAL, V. D. A.; PEDRO, H. S. P.; NARDI, S. M. T. História em quadrinhos para ensino e prevenção das doenças transmitidas por alimentos. Arquivos de Ciências da Saúde, São José do Rio Preto, v. 23, n. 2, p. 81-86, 2016. DOI: https://doi. org/gnp9. 
SILVA, K. V. L. G. et al. Training of adolescent multipliers from the perspective of health promotion core competencies. Revista Brasileira de Enfermagem, Brasília, v. 71, n. 1, p. 89-96, 2018. DOI: https://doi.org/gprf.

SILVA, L. E. L.; OLIVEIRA, M. L. C.; GALATO, D. Receptividade à vacina contra o papillomavirus humano: uma revisão sistemática. Revista Panamericana de Salud Pública, Washington, v. 43, e.22, 2019. DOI: https://doi.org/10.26633/RPSP.2019.22.

UNESCO. Educação e cuidado na primeira infância: grandes desafios. Brasília: UNESCO Brasil, 2002. Disponível em: https://cutt.ly/mmJ2Dm4. Acesso em: 15 jul. 2021. 